\title{
An Economic Perspective on the Intergenerational Transmission of Wealth Inequality
}

\author{
Kefei Lyu, ${ }^{1,2}$ Xiaoxuan Niu, ${ }^{3}$ Yucheng Zhou ${ }^{4, *}$ \\ 1. Bond Issuance and Sales Manager, Investment Banking Department, China CITIC Bank, China \\ 2. Academic Assistant, Tao Xingzhi Study Association of China (TSAC), Intelligence Education Branch, China \\ 3. Nanjing Normal University, Nanjing, China \\ 4. Monitor Business Machines, New Zealand \\ *: All corresponding should be sent to Mr. Yucheng Zhou \\ Authors' Contact: Kefei Lyu, E-mail: Ikf90016@163.com; Xiaoxuan Niu, E-mail: nxxfcy@126.com; Yucheng Zhou, E-mail: Dan- \\ iel.zhou@monitorbm.com. \\ DOI: https://doi.org/10.15354/si.21.re257 \\ The authors declare no competing interest.
}

Intergenerational transmission of wealth is a long-standing component of society. With the current accelerated economic development, the forms of wealth transmission and the ways in which it affects individuals' lives have gradually become more complicated. In this article, we explore the economic performance and basic flow patterns of intergenerational transmission. We first discuss the key factors of personal and family wealth accumulation. We then consider how social performance affects the phenomenon of intergenerational transmission and the macro-channels of the current transmission mode. Finally, while intergenerational transmission is widespread in society, its importance has not attracted widespread attention from socio-economic researchers and this paper makes suggestions for further study of the phenomena. Our main conclusion is that in current society, intergenerational transmission both directly and indirectly influences the lives of members of society in multiple ways, such as through income, employment and education. If a basic understanding of the phenomenon of intergenerational transmission can be established, it will assist people in making relevant decisions more scientifically and allow them to have a fairer life experience.

Keywords: Intergenerational Transmission; Economy; Wealth Accumulation; Inequality

Science Insights, 2021 December 28; Vol. 39, No. 5, pp.391-400.

() 2021 Insights Publisher. All rights reserved.

(i) Creative Commons Non Commercial CC BY-NC: This article is distributed under the terms of the Creative Commons Attribution-NonCommercial 4.0 License which permits non-commercial use, reproduction and distribution of the work without further permission provided the original work is attributed by the Insights Publisher.

\section{Introduction}

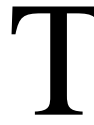

HE generation, concentration, and distribution of wealth are core social production activities affecting human development and are an important basis by which later generations use historical records to conduct phased research on social forms and historical developmental stages. Adam Smith proposed four historical periods in classical economic theory, from the earliest collection era to the industrial era, with each production stage having a unique mode of production and accumulation of means worldwide.

Enriching one's means of livelihood is thought to be part of the human survival instinct; in the era of collection and nomadic farming, the accumulation of means through livelihood was extremely limited, and largely restricted by productivity, pro- 
duction methods and the natural environment. By the time of industrial production, productivity had experienced a breakthrough in development. The products produced exceeded the requirements for satisfying the requirements for livelihood, and thus capital accumulation became possible.

The accumulation of individual wealth can be understood in a similar framework. The purpose of individual wealth accumulation ranges from satisfying basic life needs, to gradually improving quality of life, and to expansion of personal value. The methods of individual wealth accumulation develop from the simple labor of a single individual to the accumulation of tribal alliances and wealth accumulation with the help of various social relations. The results of production and development in society are reflected in the possession and transmission modes of personal and family wealth.

With the establishment of the field of economic anthropology, the role of human beings as adaptive agents in economic activities has gradually attracted more attention. Research related to economic development concerning human survival experience and development, such as social class, social equality, and wealth flow is gradually increasing. Since the financial crisis of 2008, the global economy has become more complex, and the living conditions of individuals have been affected by changes in the overall economic environment.

In the context of ever-changing circumstances, among the participants in social economic activities, people who hold a performance philosophy try to obtain better positions in social production through investment in their own value. Those who do not occupy an advantage in the distribution of social resources seek to overcome the limitations of their current class. Different groups of people are constantly making efforts for survival space and development opportunities. Assuming the total amount of social resources is finite, as the total number of people hoping to obtain resources is increasing, competition increases and inevitably a large number of people will have difficulty obtaining the expected gains, and all those involved in resource competition will face tremendous pressure.

Although the types and sources of stress affecting those who generate stress and those who face it differ, the logic of their continuous efforts is the same. Both types of people hope to obtain better resources, create a better life, accumulate sufficient material security for the future through individual efforts, and achieve a higher social class. Driven by such hopes, offspring strive to surpass their parents' wealth status, while parents have high expectations that the next generation will see higher success. The most intuitive embodiment of this drive is an upward increase in the accumulation of personal wealth from one generation to the next.

However, under the pressure to achieve their goals, people are living in very busy, and even difficult, conditions as they sacrifice their current quality of life for a certain future vision. How many of those paying such a price eventually achieve their desired goal is a metric worthy of clarity. In other words, what is the value of this upward mobility in the era of universal pursuit of surpassing the wealth class of one's parents? Without relying on the accumulation of family wealth, can an individual obtain the equivalent accumulation of wealth within the same time frame as one's parents did, or achieve the same amount of wealth with the equivalent investment?

To discuss these issues, we must first clarify the source of family wealth and then explore models of wealth accumulation. To do so requires classify people, analyzing the mode of wealth and resource circulation among people from different classes and then finally make an effective conclusion.

\section{Key Factors and Causal Logic of the Intergen- erational Transmission of Family Wealth and Capital}

Human economic activities are divided into four stages by classical economics. People in societies ranging from the gathering society to the industrial society, have always protected their means of subsistence. Such storage and transmission of acquired resources is an ingrained human instinct for life. However, as human society gradually developed from small and simple to large and complex structures, the mode of social production gradually became more complicated, and the result shows a diversified appearance. The production relationship has expanded from purely within the family to the larger social component unit; correspondingly, the status in the production relations correlates with status levels in other social components. As the phenomenon become more complicated, a return to the definitions of the basic concepts can help us better build an understanding of the economic mechanisms underlying intergenerational transmission of wealth.

\section{Key Factors in Realizing Personal Wealth Ac- cumulation}

In the field of economics, the accumulation of wealth within the family belongs to the field of microeconomics. Compound interest is a key factor in the accumulation of wealth throughout life. This is a process that allows the individual to realize continuous multiplication of wealth through economic activities. In this process, the original funds invested in financial activities, time and interest rates granted by financial institutions jointly determine the amount of growth in personal wealth.

Using this as the basic logic to expand on the concept of compound interest, the continuous accumulation of family wealth is a process of comprehensively applying all the material and non-material resources within the family to generate property proliferation. The most basic means of obtaining wealth is to engage in productive labor. In this process, the ratio of input and output is essentially balanced. However, in this preliminary production process, differences in the amount of labor obtained will create an uneven spread in the distribution of resources. People with more earned income can use their greater resources in exchange for social resources or to expand production. In this process, they also make their own resources more abundant. At this time, stratification occurs between those engaged in basic productive labor and those who enjoy wealth accumulation.

Max Weber proposed that the stratification of social resources occurs at levels other than through property ownership (1). He emphasized differences in property ownership in the market, that is, the ability to possess, control and use social resources by different groups. Starting from the influence of social resources, such as prestige and power concerning people's interests, he proposed that the possession of social resources is a 
manifestation of the degree of recognition and social influence of an individual in society. People who possess the same social resources constitute a class with common interests and they form alliances to safeguard their own interests. Those with more social resources can use their acquired social identity and social influence, through alliances with groups of the same interest and use their influence to obtain more resources. Individuals in classes with more resources have increased ability to obtain further resources to support their development, carry out economic activities and build careers. Compared to those with fewer resources, individuals in these classes can more readily further personal development and family wealth accumulation.

This kind of resource can be used by the parent to maintain the status of their offspring and to accumulate wealth. Three specific types of resource can be acquired. First is economic resources, the most representative quantitative embodiment of resources, and the most directly inheritable resource. Second is cultural and educational resources, which are a form of capital that can be used for transformation. Third are power resources, which include administrative clout, unit status, etc. that allow them to aid their offspring in acquiring resources through personal social influence (2).

With the development of science and technology, inequality in production among society members in today's world not only continue to exist but are further aggravated. At the same time, the impact of education on personal development in modern society has attracted unprecedented attention. Those who originally had advantages in cultural and educational resources will attach importance to the consolidation of existing resources; this constitutes a process of using class resources to accumulate wealth. This contrasts with those who do not originally have resource advantages, such that the resources acquired and the accumulation rate of the two groups are unequal.

\section{The Economic Logic of Wealth Accumulation within the Family}

The intergenerational accumulation of wealth within the family belongs to the category of microeconomics, while the economic growth and employment issues that are closely related to the family economic situation in the entire social dimension belong to the category of macroeconomics and are closely related to fiscal and monetary policies.

The accumulation of wealth between generations is related to numerous factors, such as social employment mobility and individual wealth accumulation, and because it is closely related to the social background and economic policies of a region, a population and its region are highly integrated. Thus, for the conceptual framework and interpretation tools of intergenerational wealth delivery, a rational framework for the intergenerational inheritance of wealth and its associated concepts has been reached

Wealth is an independent and important historical dimension of social stratification (3). One of the premises and core issues of research in the field is defining the nature of family wealth. The key concepts in this proposition and the research methods of basic modeling are challenging.

The OECD's statistical framework defines wealth as a stock of assets that is a quantitative indicator of the resources possessed, a key component of economic power (4). Income partially reflects the economic resources that can be used to support people's consumption. Income and family wealth are related, but not equivalent. Therefore, the concept of family wealth needs to be fully defined. The standard concept of wealth typically refers to the difference between the monetary value of household assets and total liabilities (5). In practice, factors such as the household assets involved and asset valuation standards make the actual measurement more complicated than the results presented in the model (6). Correspondingly, the definition of "wealth inequality" is also complicated by many factors, notably including age and time. Intra- and intergenerational wealth inequality are caused by age structure. The former is related to the individual's professional experience, and the latter is related to bequests and inheritance. Setting age as the vertical axis, and human experience as the horizontal axis, the position of macroscopic exogenous factors such as birth, education, gender, economic system, and economic environment will all have an impact on the accumulation of personal or family wealth.

Conducting research on income distribution from the perspective of economics typically starts with the income distribution of residents in society as a whole and the intergenerational mobility within micro-households. The former deconstructs the income level of residents in a certain area within a certain limited time frame. Composition pattern constructs a model to analyze the reasons for income disparity and changes in distribution pattern; it studies the influence of parents' income on children's income and the inheritance of economic levels between generations. With the enrichment of socio-economic survey data, longitudinal research on intergenerational mobility continues to expand and deepen.

The research on the relationship between two generations' economic status began in the 1960s. In 1967, Blau and Duncan conducted a deconstructive study of careers in America. They found that the income correlation between father and son was not strong (7). In 1979, Becker and Tomes proposed an estimation equation for the elasticity of intergenerational income. After that, Becker summarized a widely accepted view at the time: there is no obvious association between income in parent and children's generations (8). Subsequently it became clear that in the era when economic intergenerational research was founded, limitations of economic research data led to inaccurate results. Solonpublished consecutive studies in the 1990s proposing that the research data in the 1970s was downward biased (9). The data at the time underestimated the influence of parents on children in intergenerational income.

Jäntti et al. used the US National longitudinal survey of youth (NLSY) data, the UK National child development study (NCDS) data, and population registration data from Denmark, Finland, and Norway to estimate the intergenerational income elasticity and compare data among these six countries (10). The country comparisons showed an overall pattern of Nordic countries having the lowest intergenerational income elasticity and the highest social mobility. This is a more influential study after 2000 , with the increase of the data survey sample.

It can be seen from the perspective of empirical research that the core issue of intergenerational mobility is finding the correct metric. In economic literature, the measurement of the 
intergenerational mobility coefficient of income is usually estimated by the indicators of intergenerational income elasticity and the intergenerational income correlation coefficient. Building a data model that is accurate for these two indicators is the focus of empirical research.

The research on intergenerational economy in China relies mainly on CHIP (Chinese Household Income Survey), CGSS (China Comprehensive Social Survey), CHARLS (China National Baseline Survey Data), CFPS (Chinese Family Wealth Report of Peking University Chinese Family Tracking Survey) and CHNS (The Population Research Center of the University of North Carolina at Chapel Hill and the Chinese Center for Disease Control and Prevention jointly established a survey of the China Health and Nutrition Database). Chen, Dai, and Zhong, (2021) compiled data from the United States, Australia, Canada, Finland, Germany, Italy, Japan, South Korea, Switzerland, the United Kingdom in international comparison databases, providing several data sources that can be used for research on household wealth, including survey data, administrative management data, and cross-country comparison data.

One of the earliest research papers on Chinese household wealth was by Wang (11). His research is based on Levine's regression model:

$$
\begin{gathered}
\ln \left(y_{1 i}\right)=\alpha+\beta \ln \left(y_{0 i}\right)+\beta_{1} a g e_{0 i}+\beta_{2} a g e_{0 i}^{2}+\beta_{3} a g e_{1 i} \\
+\beta_{4} a g e_{1 i}^{2}+\varepsilon_{i}
\end{gathered}
$$

where $y_{1 i}$ is the income of children (1) in family $i, y_{0 i}$ is the income of the previous generation (0) in family $i$, age is the age of the parent or offspring generation in family $i$, and $\beta$ gives the elasticity of intergenerational income. The $\beta$ coefficients can range from -1 to +1 . If the coefficient $\beta=0$, the income of the previous generation and the next generation are not connected. In contrast, a coefficient $\beta=1$, suggests the next generation's income is completely determined by the previous generation. Negative $\beta$ coefficients indicate that offspring income has a negative relationship with parent income. The closer the intergenerational income elasticity is to 0 , the greater the mobility of intergenerational income; the closer the intergenerational income elasticity is to 1 , the lower the mobility and the stronger the social solidification.

Wang's research is based on the survey data of the Urban and Rural Residents Income Distribution Research Group of the Chinese Academy of Social Sciences from 1988 and 1995. The data model of Levine was used to inform research coefficient estimates and establish a more comprehensive data model. The intergenerational income elasticity in 1988 and 1995 were 0.384 and 0.424 , respectively. These research results incorporated the current situation of residents' intergenerational income mobility, the family background in inequality, the degree of dependence of children on their parents, household income flow trends and other specific issues.

Liu and $\mathrm{Hu}(12)$ used the intergenerational transmission model proposed by Solon (9) to integrate family financial assets, family real estate value, family lending and family liabilities as intermediate variables in a conditional intergenerational trans- mission model. The research is based on data from 2008, 2010 and 2012 from the CFPS and CHFS datasets. The conditional intergenerational transmission model was used to analyze the correlation of family financial assets, family property value, family loan and family borrowing with father and son income. The four types of household wealth variables were closely related to the income of the father and son in the two generations. Among them, real estate has the strongest explanatory power for intergenerational income mobility, followed by family financial assets, which had a greater influence on the transmission of intergenerational income.

Judging from the research patterns to date, the current intergenerational transmission of wealth can be observed hierarchically based on patterns following the emergence of social strata. Income and social resource occupation are the dividing standard in terms of obtaining income and accumulating wealth; people with vast social resources can be regarded as the upper strata and those with less income and wealth and no advantage in social resources are regarded as the lower strata. The inequality caused by the differences between different social classes is difficult to avoid at the current stage of development. This is a problem that researchers and policy makers pay attention to and this phenomenon is projected on the individual's life experience, or perception of fairness.

In both social levels, the phenomenon of intergenerational transmission exists, but the two groups differ in perceptions of the ratio of input to output. This is the objective economic and social inequality in people's subjective consciousness: the mapping of "social fairness." This also leads to a proposition about the impact of intergenerational transmission on people's life experience.

\section{The Formation and Performance of the Pattern of Intergenerational Transmission of Family Wealth}

According to the mechanism of economic intergenerational transmission, the continuous accumulation of social wealth leads the total economic volume within a generation to increase, and then the transfer of wealth from parent to offspring is completed through intergenerational transmission. Some groups will be in this situation, inheriting the wealth and resource advantages of their parents, while others will inherit the poverty and resource shortcomings of their parents. This intergenerational transmission of economic status largely reflects the development of their children. The degree of inequality in status (13), is connected to a clear sense of unfairness; however, any individual can increase their own human capital through the acquisition of resources, and thereby attain a higher economics class.

To observe the specific performance of intergenerational inheritance in society from the universal social consciousness of "a sense of fairness", we must first analyze the intergenerational income elasticity coefficient between parents and children. This value is reflected in social phenomena. The level of social mobility is directly related to people's perception of fairness. The level of social mobility can be divided into levels of absolute social mobility and relative social mobility. Absolute social mobility refers to the degree to which an individual's social class is ultimately different from the social class of their parents. Rela- 
tive social mobility refers to the degree to which individuals obtain specific results regardless of changes in the overall social class. Social mobility is divided into the macro and micro perspectives. The changes in these two values are not necessarily positively correlated. High absolute social mobility and low relative social mobility may exist at the same time. The relative mobility level is more closely related to the individual's perceived "sense of fairness".

The absolute level of social mobility is closely related to economic growth, while the relative level of social mobility is more closely related to individual development. Therefore, when observing the mode of intergenerational transmission, the core issue that needs to be clarified is whether individuals whose personal wealth is at a lower position in the overall income distribution can exceed the position of their parents in the income distribution. The possibility of offspring surpassing their parent's position depends on the offspring's late-mover advantage and the ability to catch-up growth. Correspondingly, it is necessary to clarify whether the offspring have sufficient late-mover advantage and have been caught up. In the current social environment, what are the difficulties in obtaining the advantage of the younger generations? Can the "catch-up" of catch-up growth be established, and if not, what are the obstacles?

\section{The Current Dominant Wealth Accumulation Channel}

Personal income from labor is the most important source of household wealth and the most universal way of acquiring wealth. The value of personal permanent income is dominated by the value of individual labor resources and the social selection mechanism, so these two factors should be examined at the same time when analyzing the level of personal wealth acquisition. The value of the individual labor force determines the acquisition of occupations and positions. The formation of value itself cannot be separated from the influence of parental education investment and is closely related to intergenerational transmission. The social selection mechanism is a relatively objective factor, but it has considerable flexibility. In addition to institutionalized choices, non-institutional factors will have some impact on the specific selection process. For example, a parent's use of personal social resources to assist their offspring to obtain the same value of human resources will have a greater impact on the competition for more valuable jobs.

\section{Personal Wealth Acquisition}

Individuals obtain labor remuneration through employment, and labor remuneration has also become an important source of personal wealth accumulation. Therefore, career choice has an important impact on the acquisition of personal wealth. Current society relies on specialized and refined social division of labor to set up positions. In the ideal model, workers who fit the positions and those engaged in the positions present a higher correspondence, while in the actual social selection mechanism, apart from economic rationality, the influence of the family still cannot be ignored. Career choice itself has the possibility of passing through family relationships, and income level is also passed from parent to offspring through the inheritance of profession.

Zhou and Zhang (14) established a regression model to re- flect the relationship between occupational inheritance and income mobility in modern times, $y_{i, t}=y_{i}+v_{i, t}$, where $y_{i, t}$ is the actual income of individual $i$ in year $t, y_{i}$ is the permanent income of individual $i$, and $v_{i, t}$ is the temporary income. Based on this, and according to changes in the actual research background, the permanent income influence coefficient, age influence coefficient, etc., are added to correct the data deviation, the logarithm of the comprehensive income factor is taken, the dummy variable (SameOccupation in the formula) and the age variable (age), gender (male), and education (edu) of the father and son engaged in the same occupation are included. This leads to the following regression model:

$$
\begin{aligned}
\ln \left(y_{I, S}\right)=\alpha & +\beta \ln \left(y_{i, f}\right) \times \text { SameOccupation }_{i} \\
& +\gamma_{1} \text { SameOccupation }_{i}+\beta_{2} \text { age }_{i . s} \\
& +\beta_{3} \text { age }_{i, f}^{2}+\beta_{4} \text { age }_{i . f}+\beta_{5} \text { age }_{i, f}^{2} \\
& +\beta_{6} \text { edu }+\beta_{7} \text { male }+\varepsilon_{i, S}
\end{aligned}
$$

According to the model calculation, for urban families, the intergenerational income elasticity of intergenerational occupational inheritance is 0.147 higher than that of other families. In the sample of rural families, the influence of intergenerational occupational inheritance on the elasticity of intergenerational income reached 0.195 . This reflects that the 2006 CGSS database sampled by researchers, includes occupations as an important channel of intergenerational income transmission.

\section{Parent's Investment in Children}

Furthering the accumulation of one's own human value through education is the only way for an individual to improve social status. The current professional and refined divisions of social posts have gradually increased the requirements for the education level of workers. The value returns given to workers in different job positions result in differences in occupational income. Following this logic, parents will tend to invest in education for their offspring to ensure their human resource value. When the offspring reach adulthood, they can also benefit from the social capital of the parent, which constitutes a direct inheritance of family assets.

\section{Educational Investment in Children}

In the context of modern society, the main way of transmitting family status is through the indirect inheritance of education (7). The direct manifestation of this is that families with more resources are able to provide their children with better educational resources and better education. With high levels of education and family resources at or below the median level of society, the educational resources that children obtain correspond to the average level of education provided by their social background. In other words, the average education level of society determines their education level.

In a performance-oriented job market, employees with higher education levels have a higher chance of obtaining lucrative jobs. This allows those who acquire higher levels of educa- 
tion for their children to more easily ensure that their children have a high income. This creates the possibility of a job with a higher personal permanent income level and allows offspring to continue the growth of family wealth.

Employees with a social average education level have relatively narrow career choices, and are more likely to achieve relative class mobility, that is, an economic relationship between children and parents. In the context of a comprehensive social and economic improvement, this allows upward mobility within the family. It is more difficult to achieve an absolute increase in the economic level of the offspring in this socio-economic hierarchy compared to the parent generation.

\section{The Indirect Role of Social Capital}

French sociologist Bourdieu (15) first introduced the concept of "social capital" into the field of sociological research and expanded the definition of "capital" proposed by Marx in Capital, defining it as "a collection of actual or potential resources" that incorporates other productive factors besides material into the definition of "capital." For intergenerational transmission, in addition to economic inheritance, which is the most direct method of inheritance, and education investment, which has a strong correlation with inheritance, social capital is a third important transmission channel affecting intergenerational economic levels. The intergenerational transmission of social capital refers to the social capital of parents, the basic elements that constitute social capital, and the conditions for forming social capital. It is passed from parents to children within the family, so that children obtain a stock of social capital similar to that of their parents when they become adults. If the social capital of the previous generation is enriched, the social capital of the next generation will also be enriched, and vice versa (16).

As society develops, the effectiveness of direct inheritance of economic wealth begins to give way to the inheritance of social capital, allowing children to use their parents' social capital stock to give them a more solid foundation for development and accumulation of more wealth. Social capital can complete the transformation of non-material capital to material capital through various forms and allow further expansion of social capital stock through the accumulation of material capital. When this process exists in a relatively fixed group, a class is formed, and a divide created between the superior class and the relatively inferior class (17).

Each stratum will carry out stratum reproduction. The goal of the superior stratum is to maintain intergenerational transmission of resources, and then maintain its own resource advantages. The goal of the relatively disadvantaged stratum is to break through the current transmission mode and advance but, due to the acquisition of resources, the process is far more difficult than for the dominant class, and it is also more difficult to achieve a breakthrough within the existing class.

The above two indirect inheritance methods of capital have strong explanatory power for the degree of personal wealth accumulation. The economic capital and social capital of parents are strongly correlated with offspring career choice and labor acquisition but under this mechanism, the role of different groups of people differs. In those with a certain amount of wealth accumulation, resources accumulated by the parent are passed on to the offspring, allowing them to maintain the same standard of living of their parents, and potentially move up a class. This inheritance method occurs when wealth accumulation is relatively scarce in the group of people; children often inherit the dilemma of their parents, which constitutes a negative inheritance. This inheritance mechanism, in the absence of policy adjustments and other external forces, will inevitably aggravate the inequality between social groups. The degree of this inequality and the impact on people's sense of fairness will differ in different times and social backgrounds.

Offspring that hope to surpass their parent's economic or resource class, typically need sufficient late-comer advantages to succeed. The acquisition of such advantages is often based on family financial behavior or educational investment that enhance the human resources value of the offspring. This creates competition for positions with remuneration advantages.

The inheritance and mobility of occupations between generations is the link that connects the incomes of parents and offspring, and this constitutes a key link in explaining the mobility of intergenerational income. At the same time, employee positions with abundant incomes do occur and these occupations often have high job search thresholds and lack mobility. Family background and social network play an important role in the job search process for children. Career inheritance between generations is a common phenomenon, allowing children to be completely separated from each other. The restricted freedom for offspring to obtain positions independently has created greater resistance to changes in social class.

If the total amount of resources is relatively stable, the number of people participating in resource competition will continue to increase, and the proportion of people who obtain resources will continue to decrease. At the same time, the increase in competitors, will lead to the increasing side effect of the devaluation of human resources and occupational gains.

These two aspects simultaneously restrict the competitor's acquisition of late-mover advantage.

\section{An Intergenerational Flow Model That Blends Multiple Forms of Delivery}

In modern society, the general development trend is to screen personnel and assign jobs based on the principle of performance. Based on this, the standards for users can be divided into two categories: performance-based and other principles. The distinction is made according to whether the government intervenes. $\mathrm{Li}$ (18) put forward three ideal types of intergenerational mobility based on the theory of western intergenerational mobility. First is the competitive mobility model under the performance principle. Second, is the family status inheritance model under the social inequality structure. Third is the mode of national asylum mobility under the socialist ideology. At the same time, Li (18) uses the three factors of parental economic status $(\mathrm{O})$, offspring education (E) and offspring economic status (D) to build an OED relationship model. Using an analysis of the relationship between the three elements of the person, provides a good way to describe the coordinates of the current generational transmission mode.

China has clearly experienced all three types of intergenerational mobility, and as the background of the times changes, 
they blend and appear in the current context. In the past hundred years, China first adopted the socialist ideology of the country's asylum mobility model to reduce overall social inequality and weaken the role of family background in intergenerational transmission through changes in social structure. Education and career choices affect the family and these factors have had a major impact on wealth accumulation, as determined by policy planning. After the 1980s, with the gradual unfolding of the market economy, economic rational performance factors began to appear in society. The market had the right to choose employment. The equality of the market is over-selected by the market and this process puts forward demands for the education level of personnel and strengthens the weight of education in the occupational acquisition process. At the same time, people who obtain wealth higher than the social average at this stage can transfer their accumulated wealth, passing it on to the children.

However, after entering the 21 st century, with the development of productivity and the diversification of production relations, the original relatively simple intergenerational mobility model has become complicated over time in the process of social screening and opportunity distribution in the mainstream of society. Based on the individual's inherent qualities, abilities, and work skills, the family status inheritance model begins to take effect in the form of indirect inheritance of social and cultural capital. The parent's economic status gives offspring a better education, which in turn means offspring can also have a good economic status $(\mathrm{O} \rightarrow \mathrm{E} \rightarrow \mathrm{D})$. At the same time, policies still play a role in guiding resource allocation in intergenerational mobility through the regulation of education and some occupations. Therefore, it can be said that in China, the mode of macroscopic observation of intergenerational mobility is intertwined with multiple forms, and their respective influences are constantly changing.

In different groups of people, the power of intergenerational transmission also has different manifestations. Because of China's unique urban and rural duality model, the generational differences that accompany differences in the population and in identities are more specific. Some research by Chinese scholars has focused on the intergenerational differences in the employment of rural people in urban areas.

For the research on inter-generational income flow, Zhou and Zhang (14) explored the mode of intergenerational flow and the manifestation of income flow in Chinese urban and rural households from a professional perspective. The study focused on the split population of China's urban and rural areas. Policy makes the urban and rural occupation inheritance high, but flow between urban and rural areas has characteristics of openness. $\mathrm{Wu}(19)$ measured the intergenerational occupational mobility index and the intergenerational occupational inheritance index, finding that the inheritance of occupations is more obvious in jobs with higher professional skills and in career choices such as business and agriculture; and it is defined as "general clerk" and the mobility of which is relatively high.

Ma and Zhang (20) surveyed the employment of migrant workers in Jiangsu, Zhejiang, and Guangdong, and studied the intergenerational differences in employment quality. Du and Liu (21) observed in Eastern, Central and Western China, Tianjin, Shanghai, and Guangzhou. The impact of occupational mobility on the income of migrant workers in the seven cities of Wuhan, Harbin, Chengdu, and Lanzhou. At present, China's research on the intergenerational transmission of occupations and incomes among specific groups of people mainly focuses on the employment and income of rural migrant workers in urban areas. It reflects that even though the overall level of social development is relatively high, compared to the parent generation, the employment quality and the economic level of the offspring generation in underdeveloped areas increased relatively, and it remains difficult for them to achieve an absolute rise in status.

Most research on intergenerational transmission in China focuses on the urban population and/or urban employment positions. This is determined by the relative ease of statistics and classification of urban population and positions, and the situation of production and occupational settings in rural areas. Both rural components are relatively complicated, difficult to conduct research, and long-term. Therefore, the current pattern of intergenerational transmission in rural China has not been clearly outlined.

\section{The Influence of Intergenerational Transmis- sion on Personal Life Experience}

Occupation, income, and education are the main factors on which members of society base their sense of justice. These three items are closely related to the number of resources that people have and the fairness of the resources they obtain. A sense of justice reflects a comparison between people and comparable groups with similar social resource endowments, combined with measurement of fairness of access to resources by the self and others.

Zhang and Zhu (22) proposed that the fairness of distribution is affected by the intergenerational resource possession. People's perception of the amount of resource possession is a combination of parental resources and their own resources. They point out intergenerational wealth and society. The relationship between resource accumulation and perception of fairness. Multinomial logistic regression (mlogit), binary logistic regression (logit) and generalized structural equation (gsem) models are used to analyze the influence of intergenerational mobility on the perception of fairness of wealth distribution among Chinese urban residents. The research suggests that the trajectory of intergenerational flow affects people's sense of distribution fairness through the path of resource acquisition opportunities and the path of possession of intergenerational resources; the upward flow of intergenerational transmission and upper-level stability creates more opportunities for resource acquisition, higher relative status, and a subjective upward mobility with a lower sense of distributional unfairness. In contrast, intergenerational downward mobility increases urban residents' sense of unfair distribution and the sense that those who are prevalent and stable at the upper level have more intergenerational resources and a higher sense of fairness in distribution. At the same time, the study author contends that promoting intergenerational occupational mobility can avoid the disadvantages of intergenerational inheritance to a certain extent, comprehensively utilize occupational resources in different regions, broaden employment channels, and reduce the occurrence of "intergenerational low-income inheritance traps" among low-income groups, 
thereby enhancing the sense of fairness of distribution among urban residents.

\section{Conclusions and Insights The Objectivity of the Phenomenon of Inter- generational Transmission}

The accumulation of wealth between generations is a relatively neutral concept. The enrichment of wealth that can occur in a generation is the result of the accumulation of production and high-quality resources in society. The long-term transmission of high-quality resources between generations that exceed the regulation of economic laws or the mobility of education, administration, etc., solidifies socio-economic strata, leading society to become rigid.

In a social background where resources are relatively scarce and concentrated, intergenerational inheritance can ensure the effective use of core social resources in key positions and achieve social breakthrough developments with more intensive resources; at the same time, the stability of population migration will make the intergenerational resource transfer coefficient high. The stability of the population will thus reflect to some extent the greater proportion of the population with improved living conditions, which is one of the manifestations of the gradual stability of social composition.

\section{Two Sides of the Influence of Intergenerational Transmission}

The influence of wealth transmission between generations has two sides. Under different historical stages and policy backgrounds, the pros and cons have intergenerational transmission have different manifestations. Researchers have also put forward views based on their pros and cons.

First, the dominant form of intergenerational transmission in different historical stages changes, from the accumulation of material to the transmission of capital, to the inheritance of today's cultural and social capital, which has a greater impact due to its reproductive capabilities.

Both the pros and cons of intergenerational transmission of cultural and social capital have strengths and weaknesses and the two sides of their influence have been widely discussed. American sociologist Coleman (23) focuses on the aspect of social capital that can be used in social life and generates more value. He believes that social capital is: "defined by its function. It is not a kind alone - they are different entities with various forms. They have two common characteristics: they are composed of the various elements that constitute the social structure; they provide convenience for individual actions within the structure." In this discourse, social capital itself and its inheritance is a mode of comprehensive utilization of resources, using its own productivity to achieve development goals. Coleman (23) also points out that the characteristics of this form of capital "exist in interpersonal relations; it is neither attached to independent individuals, nor in the process of material production." The dependence on interpersonal relations is the capital. The prerequisite for form to have an effect; in other words, the close connection between generations facilitates this form of capital and its value conversion.

Portes (24) describes tit-for-tat and its critical perspective on the definition of social capital. "Social capital refers to individuals in the network or broader social structure through their membership. The ability to obtain scarce resources is not inherent to the individual, but an asset contained in the relationship between the individual and others." This view emphasizes the imbalance in the distribution of social capital. Relying on interpersonal relationships, mobility is limited, which can easily cause social capital and material wealth reproduced by social capital to be passed on from generation to generation, leading to wealth condensing in a fixed class and causing class differences. "Unevenness" within a certain range will not have an excessive impact on people's quality of life. However, when the same group of people is fixed in a certain stratum in the social income hierarchy for a long time, it will lead to poor mobility. Social mobility is an important dimension that affects people's social attitudes (25). The existence of the "ceiling effect" in a society with low mobility for a long time will erode people's motivation to strive for a better life.

The stage of resource enrichment in intergenerational transmission may lead individuals to speculatively pursue some types of high-value product. Research by $\mathrm{Liu}$ and $\mathrm{Hu}$ (12) showed that a large proportion of intergenerational transmission mechanisms in family wealth depend on the value of real estate and family financial assets. Therefore, a large number of consumers target wealth accumulation rather than using real estate solely for housing. The goal is to join the real estate market, leading to the expansion of housing beyond the rigid needs of survival to expand financial assets. At the same time, housing is linked to urban location resources, which links the value of housing from the economic field to the social resource field and repeated reproduction of social capital and wealth capital. This reproduction is passed on through generations of real estate sovereignty and transmitted by parents. In the children's generation, a double closed flow of wealth resources and social resources is formed.

\section{The Complexity of the Impact of Intergenera- tional Transmission on Real Life}

Intergenerational transmission creates socio-economic imbalance and is associated with a class differentiation problem; together these combine to affect people's "sense of fairness." This generates an emotional component for parents making economic or child education investment decisions and when a number of groups have commonalities in the choices, the joint results of this selection mode are often drastic and unpredictable.

Since the mechanism of intergenerational transmission affects people's daily life through economic activities, career choices, educational investment, and social resource influence, it is necessary for both policy makers and members of society to thoroughly understand the transmitted attributes and mechanisms of intergenerational transmission of wealth and use them as reference factors to assist in decision-making.

The phenomenon of intergenerational transmission frequently appears in social, economic, and cultural life, implicitly or explicitly, from the direct transmission of initial property and the diversification of social production deriving indirect transmission modes such as position transmission and education transmission. To formulate a reasonable career plan, participants 
in social life need to understand the relationship between intergenerational transmission and their own life, and its relationship to their career goals. At the level of family asset accumulation, financial knowledge should be used to rationally allocate family assets to promote family wealth accumulation (26). In terms of career choice, intergenerational inheritance, and mobility of the target occupation, combined with the degree of application of the performance principle can help eliminate highly closed occupations and allow the acquisition of jobs more quickly.

At the level of policy formulation, comprehensive control of intergenerational transmission and accompanying phenomena can better allocate social resources effectively. In the superior class, high-quality resources are abundant and easy to mobilize for reproduction, but the utilization of resources and the people who can benefit from the resources are a minority in society as a whole; the lower class has difficulties obtaining resources. This kind of cross-border resource allocation can make the minimum resources available to individuals of higher quality through the overall economic development; it can also weaken the family background through policy allocation and use effective tools such as education to interfere with social change. The role of equal transmission (27), taxation and welfare policies can also be used to carry out the secondary distribution of social wealth to change the inequality structure in society.

A comprehensive understanding of the display form and role of intergenerational transmission in the current stage of development can avoid blind investment led by purely goal-oriented development, so that different groups will not rely on the current quality of life while seeking to build the future. This will establish clearer, rational thinking about development opportunities and obstacles to goal achievement, promoting the establishment of strategic problem solving using an objective awareness of economic reality.

\section{References}

1. Weber M. From Max Weber: Essays in Sociology. London: Routledge. 2009.

2. Bian YJ, Lu Q. Social stratum reproduction and intergenerational transmission of resources. People Forum 2014; 2014(2):20-23. DOI: https://doi.org/10.16619/j.cnki.rmlt.2014.02.038

3. Killewald A, Pfeffer FT, Schachner JN. Wealth Inequality and Accumulation. Ann Rev Sociol 2017; 43:379-404. DOI: https://doi.org/10.1146/annurev-soc-060116-053331

4. OECD. OECD Framework for Statistics on the Distribution of Household Income. Consumption and Wealth. Paris: OECD Publishing. 2013. DOI: https://doi.org/10.1787/9789264194830-en

5. Cowell FA, Van Kerm P. Wealth inequality: A survey. Journal of Economic Survey, 2015; 29(4):671-710. DOI: https://doi.org/10.1111/joes.12114

6. Chen Y, Dai XT, Zhong CC. A theoretical and empirical study on residents' wealth inequality. J Jiangxi Finan Coll 2021; 34(2):3-16.

7. Blau PM, Duncan OD. The American Occupational Structure. NY: Wiley. 1967.

8. Becker G, Tomes N. An Equilibrium Theory of the Distribution of Income and Intergenerational Mobility. J Polit Econ 1979; 87(6):1153-1189. DOI: https://doi.org/10.1086/260831

9. Solon G. Chapter 29- Intergenerational mobility in the labor market. In O. C. Ashenfelter \& D. Card (Ed.), Handbook of Labor Economics, 1999; Volume 3, Part A (pp.1761-1800). Elsevier. DOI: https://doi.org/10.1016/S1573-4463(99)03010-2

10. Jäntti M, Bratsberg B, Røed K, Raaum O, Naylor R, Österbacka E, Björklund A, Eriksson T. American exceptionalism in a new light: A comparison of inter-

generational earnings mobility in the Nordic countries, the United Kingdom and the United States. The Warwick Economics Research Paper Series (TWERPS) 781, University of Warwick, Department of Economics. 2007.

11. Wang HG. Intergenerational mobility of income distribution in China. Econ Sci 2005; 2005(2):18-25. DOI: https://doi.org/10.19523/j.jjkx.2005.02.002

12. Liu JH, Hu YF. Intergenerational transmission of residents' income based on family wealth capital. Zhejiang Finan 2014; 2014(9):11-16.

13. Zhang YQ, Eriksson T. Inequality of opportunity and income inequality in nine Chinese provinces, 1989-2006. Chin Econ Rev 2010; 21(4):607-616. DOI: https://doi.org/10.1016/i.chieco.2010.06.008

14. Zhou X, Zhang P. Intergenerational occupation mobility and income mobility -- An Empirical Study from urban and rural families in China. Economics (Quarterly), 2015; 2015(1):351-372. DOI:

https://doi.org/10.13821/j.cnki.ceq.2015.01.018

15. Bourdieu P. Cultural Capital and Social Alchemy (Chinese Edition). 1997. Shanghai: Shanghai People's Publishing House.

16. Cheng W, Niu XX, Chi PX. Intergenerational trans-mission of social capital. J East Chin Univ Sci Technol (Soc Sci Ed), 2013; 2013(1):1-9.

17. Sun LP. Cleavage. Beijing: Social Sciences Academic Press (China). 2002

18. Li Y. The pattern of intergenerational mobility: Theoretical ideal and Chinese reality. Society 2009; 2009(6):60-84 + 223-224. DOI: https://doi.org/10.15992/j.cnki.31-1123/c.2009.06.005

19. Wu XG. China's household registration system and intergenerational occupation mobility. Sociol Stud 
2007; 2007(6):38-65 + 242-243. DOI:

https://doi.org/10.19934/i.cnki.shxyj.2007.06.003

20. Ma JQ, Zhang HR. Intergenerational differences in employment quality -- Based on the survey data of migrant workers in Jiangsu, Zhejiang, and Guangdong. Fujian Forum (Human Soc Sci) 2014; 2014(6):200-204.

21. Du YD, Liu YW. The impact of occupation mobility on the income of migrant workers and its intergenerational differences -- Based on the survey data of seven cities in China. J Nanjing Agricul Univ (Soc Sci Ed) 2015; 2015(4):43-52 + 132

22. Zhang S, Zhu Y. Intergenerational mobility footprints and perception of distributive equity -- influential mechanism and empirical analysis. Sociol Rev Chin $2021 ; 2021(3): 199-218$.
23. Coleman JS. (1999). The Foundation of Social Theory. Cambridge, MA: The Belknap Press of Harvard University Press.

24. Portes A. Sociology capital: Its origins and application in modern sociology. Ann Rev Sociol 1998; 24:1-24. DOI: https://doi.org/10.1146/annurev.soc.24.1.1

25. Ganzeboom HB, Treiman DJ, Ultee WC. Comparative intergenerational stratification research: Three generations and beyond. Ann Rev Sociol 1991; 17(1):277-302. Available at: https://www.jstor.org/stable/2083344

26. Wu Y, Peng CY, Yin ZC. Financial knowledge, wealth accumulation and household asset portfolio. Modern Econ Sci 2016; 2016(4):19-29 + 124-125.

27. Parkin F. Class Inequality and Political Order. London: Holt, Rhinehart and Winston. 1971.

Received: August 10, 2021 | Revised: October 20, $2021 \quad$ Accepted: November 04, 2021 